\title{
Game-Centred Study Using Eigenvector Centrality in High-Level Women's Volleyball: Play Efficacy is Independent of Game Patterns... Or is it?
}

\author{
Lorenzo Laporta', Beatriz Valongo², José Afonso², Isabel Mesquita ${ }^{2}$
}

Affiliations: 'Universidade Regional Integrada do Alto Uruguai e das Missões, Santiago, Brazil, ${ }^{1}$ University of Porto, Faculty of Sport, Centre for Research, Formation, Innovation and Intervention in Sport, Porto, Portugal

Correspondence: L. Laporta, Regional Integrated University of Upper Uruguai and Missions, Batista Bonoto Sobrinho Street, 97700-000, Santiago/RS, Brazil. E-mail: laportalorenzo@gmail.com

\begin{abstract}
In sports, it is often assumed that distinct game patterns may influence the outcome of the play differently. However, a few articles about men's volleyball have suggested that play efficacy may rely more on the quality of individual attack actions, and not on game patterns. Therefore, the goal of this paper was to scrutinize if and how game patterns influence play efficacy in high-level women's volleyball. Eigenvector Centrality was assessed to integrate direct and indirect relationships between games actions. Thirteen matches from the women's World Grand Prix'2015 were analysed (46 sets; 2,016 plays). Actions were categorized according to game complex (K0 to KV) and three levels of the efficacy of each play: error, continuity, and point. The results showed that play efficacy was independent of game patterns (the central pattern was non-ideal setting conditions in all complexes and preference for using slow attacks in the extremities of the net). There were, however, some regularities for each game complex. For example, while in $\mathrm{KI}$ to $\mathrm{KIII}$, Zone 4 was the most used attack zone, in KIV and KV there was a complete inversion to Zone 2. Moreover, results revealed that women's volleyball games are more predictable in relation to the play space (attack zones) while increasing the risk through enhanced game speed (attack tempo), in comparison with what studies in men's volleyball have shown. Future studies should consider situational variables (e.g., match status, home vs away matches), and individual players' actions should be considered in order to understand their relationships with team patterns better.
\end{abstract}

Keywords: performance analysis, network analysis, efficacy, game complexes, game patterns

@MJSSMontenegro

GAME PATTERNS INFLUENCE PLAY EFFICACY IN WOMEN'S VOLLEYBALL

http://mjssm.me/?sekcija=article\&artid=208

Cite this article: Laporta, L., Valongo, B., Afonso, J., \& Mesquita, I. (2021). Game-Centred Study Using Eigenvector Centrality in High-Level Women's Volleyball: Play Efficacy is Independent of Game Patterns... Or is it? Montenegrin Journal of Sports Science and Medicine, 10 (1), 19-24. doi: 10.26773/mjssm.210303

\section{Introduction}

The quest for improving sports performance has motivated research focused on using Match Analysis (MA) to reveal performance indicators that provide a broader understanding of the game and, consequently, deliver novel know-how and tools for optimizing training processes (O’Donoghue, 2009). Analysis of the efficacy of game actions has been very well researched in sports (Mesquita, Palao, Marcelino, and Afonso, 2013; Silva, Marcelino, Lacerda, and João, 2016). In attempting to find correlates of efficacy, research has focused on the 
analysis of movement patterns, player position, competitive level, scoring system, gender, opposition quality, match status, match local, match outcome, among others potentially contributing factors (Marcelino, Sampaio, and Mesquita, 2011; Silva et al., 2016).

In this vein, Social Network Analysis (SNA) has been regarded with growing interest in the sports context (Wäsche, Dickson, Woll, Brandes, 2017; Yamamoto \& Yokoyama, 2011). Although there are six-dimensions in a conceptual typology of SNA applications (see Wäsche et al., 2017), competition networks (informing about the competitive outcome through patterns of interaction between athletes and/or teams) and interaction networks (how the relationships established between the players alter the outcome) are predominant in sports. Within SNA, Eigenvector Centrality is a measure that assists in establishing a more detailed relational overview of a network, since it properly weights both the direct and indirect connections of the nodes (see Bonacich and Lloyd (2001); Wasserman and Faust (1994), which is important, because in team sports game actions can produce diverse direct and indirect consequences (Cotta, Mora, Merelo, \& Merelo-Molina, 2013). Furthermore, it is possible to use SNA to treat game actions as nodes and their relations as edges, and research in volleyball has adopted both this game-centred approach and the application of Eigenvector Centrality (Hurst et al., 2016; Laporta, Afonso, \& Mesquita, 2018a, 2018b; Loureiro et al., 2017). However, only one has used eigenvector centrality to understand how game patterns influence play efficacy in high-level men's volleyball, analysing the games of the 2015 men's World League Final Phase (Laporta, Afonso, Valongo, \& Mesquita, 2019).

A wide body of research has suggested that different game patterns may be associated with debilitated opposition and therefore increase the chances of success (e.g., Marcelino, Mesquita, and Afonso (2008); Mesquita and Graça (2002). However, the study of Laporta et al. (2019) showed that play efficacy was independent of game patterns in high-level men's volleyball, perhaps due to a stronger reliance on the individual skill of the attackers (Afonso \& Mesquita, 2011; Mesquita \& Graça, 2002), which might be explained by the fact that volleyball is a sport in which the teams cannot invade the opponents' space; therefore, the attacker will ultimately have some room for acting without a very pressing opposition (Mesquita \& Graça, 2002; Queiroga, Matias, Greco, Graça, \& Mesquita, 2005).

Some researchers have used SNA and adopted different analysis metrics considering the relationship between direct and indirect connections in high-level women's and men's volleyball (Hurst et al., 2016; Loureiro et al., 2017). However, these studies, despite simultaneously considering both connections, do not provide a global game view, fragmenting into smaller frames, (i.e., the relationship between some game complexes). Nevertheless, only one study carried out on men's volleyball analysed the game flow through the global game relationships (both direct and indirect) to understand the play's efficacy (Laporta et al., 2019), making it pertinent to conduct studies in women's volleyball. Therefore, the purpose of this follow-up study was to understand if and how different game patterns impact the efficacy of each play in high-level women's volleyball, following the methodology we previously used in our study of high-level men's volleyball (Laporta et al., 2019).

\section{Methods}

Participants

The sample totalled 2,049 plays (46 sets) from 13 matches of the final phase of the 2015 Edition of the World Grand Prix (teams: Brazil, USA, Italy, China, Japan and Russia), with 2,016 actions. The network was built with 127 nodes and 2153 edges. A play should not be mistaken for a rally: the former refers to each ball possession on the part of a team, while the latter is the collection of plays within the same disputed point. This study was approved by the Ethics Committee at the Centre of Research, Education, Innovation and Intervention in Sport of University of Porto (CEFADE 16.2017).

\section{Measures}

Game Complex (K) encompassed: K0 (serve), KI (sideout), KII (side-out transition), KIII (transition), KIV (attack coverage) and KV (freeball/downball) (Hurst et al., 2016; Laporta et al., 2018a; Loureiro et al., 2017). In Complex 0, Initial Position of the Server (i.e., Zones 1, 6 or 5) (Quiroga et al., 2010) and Serve Type were considered: float jump serve (i.e., without ball rotation), jump serve (i.e., with ball rotation) and standing serve (i.e., without jumping) adapted from the work of Costa, Afonso, Brant, and Mesquita (2012).

The Zone of First Contact emerged in Complexes I, II, and III and followed the six zones defined of the court as defined by FIVB rule, but added the Others Zone (OT), corresponding to the area outside the court, where the athlete can recover the ball after a touch in the block, for example. In Complexes II and III, Block Opposition was adapted from Afonso and Mesquita (2011): i) BO - no-block, ii) B1 - simple Block, iii) B2 - double block; and iv) B3 - triple block.

The following variables appear in Complexes I, II, III, IV, and V. Setting Condition evaluates the relative quality of the first contact, linking it with the attacking options: (i) A - all attack options available; (ii) B - some attack options, such as crossings, are not possible but quick attacks are; and (iii) $\mathrm{C}$ - the setter can only use high sets (adapted from Hurst et al. (2016)). Attack Zone was evaluated according to the FIVB official zones - (Zones 1 to 6). Attack Tempo concerns the synchronization between setter and attacker: i) Tempo 1 - attacker jumped before/same time to the set; ii) Tempo 2 - two steps approach is performed by the attacker after the set; and iii) Tempo 3 - the attacker waited for the ball (ascend movement) and after that executed a three- or more-steps approach (simplified from G. Costa et al. (2012).

Specifically, in Complex IV, the following variables were considered: Available Players Before Attack Coverage showed the available players to attack before of the attack coverage happened (adapted by Laporta, Nikolaidis, Thomas, \& Afonso (2015)); Number of Coverage Lines was analysed the imaginary lines (from the net until the endline) created by the players in defence position at the attack moment (Laporta et al., 2015). In Complex V, the Freeball (offensive organization after the ball that will have to be returned softly by the opponent, due to poor conditions for performing the third contact) and Downball (attacker was unfavourable to attack, but still can perform a standing spike) (Loureiro et al., 2017); and KV Target Zone (the zone where the ball landed being an offensive or defensive zone).

The Efficacy of each game complex reported the outcome of each complex: i) E0 - error; ii) E1 - continuity; and iii) E2 scoring a point (Laporta et al., 2019). 
Table 1. Synthesis of variables, categories and codes

\begin{tabular}{llc}
\hline \multicolumn{1}{c}{ Variable } & \multicolumn{1}{c}{ Category } & For Example \\
\hline Game Complexes (K's) & K0-KV & KI \\
Initial Position of the Server & Zones 1, 6 or 5 & KOSZ5 \\
Serve Type & Float Jump, Jump and Standing. & KOSTJ \\
Zone of First Contact (reception or defence) & FIVB Six official zones; Others Zone, OT & KIFC1 \\
Setting Conditions & SC A; SC B and SC C. & KISCA \\
Attack Zone & FIVB Six official zones & KIAZ3 \\
Attack tempo & AT 1, AT 2 and AT 3 & KIAT1 \\
Block Opposition & BO - no-block; B1 - individual block; B2 - double block; and B3 - triple block. & KIINB11 \\
Available Players Before Attack Coverage & KIVAP1, KIVAP2, KIVAP3 and KIVAP4. & KIVAP1 \\
Number of Coverage Lines & KIVL1, KIVL2, KIVL3 and KIVL4 & KIVL2 \\
Freeball or Downball & KVD and KVF & KVD \\
KV Target Zone & KVAZ (offensive) and KVDZ (defensive zone). & KVAZ \\
Play Efficacy & E0 - error; E1 - continuity of action; and E2 - scoring a point. & \\
\hline
\end{tabular}

Note: The code begins with the complex that the action took place (KO-KV); shortly thereafter, the abbreviation of the variable and lastly its category. For example, KOSTJ - Serve Type - Jump in KO.

\section{Design and Procedures}

Matches were obtained from the websites laola.tv and youtube.com, recorded from a lateral side view of the court (aligned with the net with movement on both sides) in high definition (1080p). The instrument was previously validated, tested and applied by Laporta et al. (2018a); (2018b); Laporta et al. (2019).

\section{Statistical Analysis}

A descriptive analysis was conducted to ensure data quality (verify input errors, data frequency and others). Social Network Analysis techniques were applied using Gephi@ 0.8.2beta for Mac (Version 10.10.3, MacRoman, France). Nodes' size and colour were perfected to visually reflect the magnitude of their Eigenvector values used to identify the most influential nodes in the network. Edges were also depicted with a stronger intensity in order to reflect Eigenvector values better. As such, calculation of Eigenvector Centrality implies a stan- dardization process (Bonacich \& Lloyd, 2001; Freeman, 1979), in which all the actions of all the game complexes contributed to the analysis, thus providing a more precise view of how the variables contribute and influence different levels of effectivity. Therefore, this centrality measure will show the results of the interaction patterns between the variances (Duch, Waitzman, \& Amaral, 2010), aiding in determining if the analysed actions influence the effectiveness of the team.

Inter-observer reliability was calculated with the analysis of $10 \%$ of the total sample (total of 210 actions) as suggested in the literature (Fleiss, Levin, and Paik (2013)), having presented Cohen's Kappa values above 0.75 for all variables.

\section{Results}

The established networks present the Eigenvector values for each level of efficacy (i.e., 0,1 or 2). The network below (Figure 1) reveals game patterns for Efficacy 0 (Error).

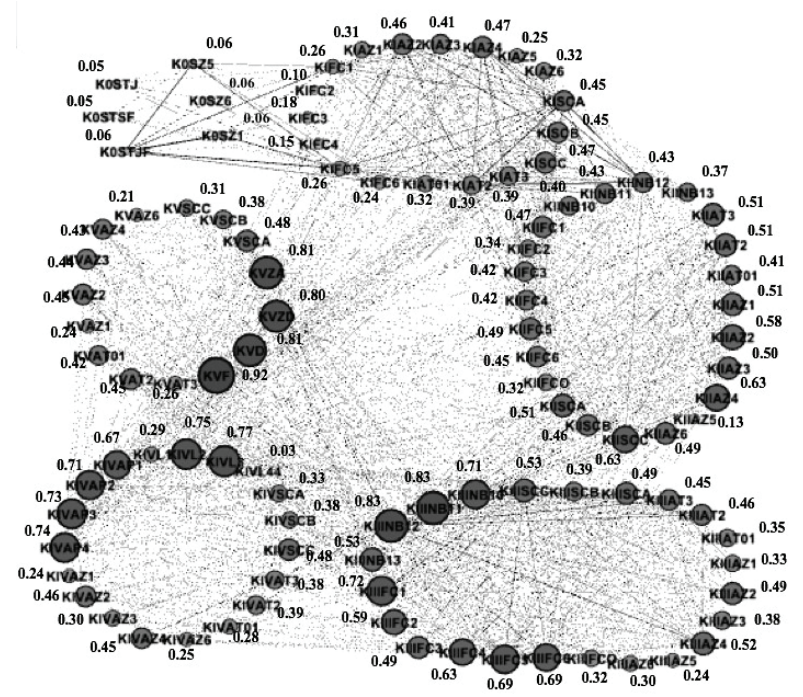

FIGURE 1. Network with Eigenvector Centrality for all variables related to the efficacy 0 in women's volleyball. Terminology: in each node, codes are represented by the name of complex (e.g., KII), followed by the variable and its category (e.g., KIIAZ6 indicates that the action occurred in complex II, the variable in question was Attack Zone, and the category is Zone 6). Codes for the different variables: IPS - Initial Position of the Serve; ST - Serve Type (Jump, Jump-Float and Standing-Float); FC - Zone of First Contact; SC Setting Condition; AZ -Attack Zone; AT - Attack Tempo; BO - Block Opposition; KIVB - Number of Available Player Before of Attack Coverage; KIVL - Number of Coverage Lines; KVD and KVF - Downball and Freeball; KVTZ -Target Zone in KV (Attack or Defence Zone). 
Eigenvector values have highlighted for Efficacy 0 (i.e., error; Figure 1): (i) Serve Type Jump Float (0.06) in K0; (ii) Setting Condition C in KI (0.36), KII (0.52), KIII (0.65) and KIV (0.48); Setting Condition A in KV (0.46); (iii) Attack Zones 4 and 2 in $\mathrm{KI}(0.30$ and 0.39$)$, KII (0.41 and 0.43), KIV (0.52 and $0.49)$, KIV (0.46 and 0.40), and KV (0.31 for both); in KIII,
Attack Zone 4 (0.48) was followed by Zone 1 (0.48); (iv) Attack Tempos 2 and 3 in KI (0.39 both), KII (0.51 and 0.51), KIII (0.46 and 0.45), and KIV (0.39 and 0.38); Attack Tempos 2 and 1 in $\mathrm{KV}(0.45$ and 0.41$)$.

The game patterns related to Efficacy 1 (Continuity) is presented in Figure 2.

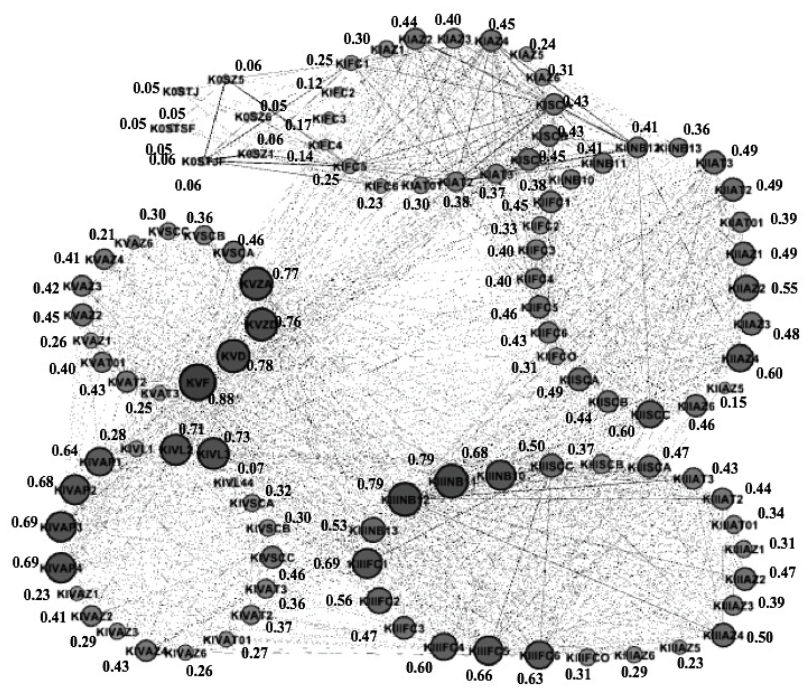

FIGURE 2. Network with Eigenvector Centrality for all variables related to the efficacy 1 in women's volleyball. Terminology: in each node, codes are represented by the name of complex (e.g., KII), followed by the variable and its category (e.g., KIIAZ6 indicates that the action occurred in complex II, the variable in question was Attack Zone, and the category is Zone 6). Codes for the different variables: IPS - Initial Position of the Serve; ST - Serve Type (Jump, Jump-Float and Standing-Float); FC - Zone of First Contact; SC Setting Condition; AZ -Attack Zone; AT - Attack Tempo; BO - Block Opposition; KIVB - Number of Available Player Before of Attack Coverage; KIVL - Number of Coverage Lines; KVD and KVF - Downball and Freeball; KVTZ -Target Zone in KV (Attack or Defence Zone).

Eigenvector values have highlighted for Efficacy 1 (i.e., continuity): (i) Serve Type Jump Float (0.06) in K0; (ii) Setting Condition C in KI (0.45), KII (0.60), KIII (0.50) and KIV (0.46); Setting Condition A in KV (0.46); (iii) Attack Zone 4 in KI (0.45), KII
(0.60), KIII (0.50), and KIV (0.43); AZ 2 in KV; (iv) Attack Tempo 2 in KI (0.37), KII (0.49), KIII (0.44), KIV (0.37), and KV (0.43).

The game patterns associated with Efficacy 2 (point) is presented in Figure 3.

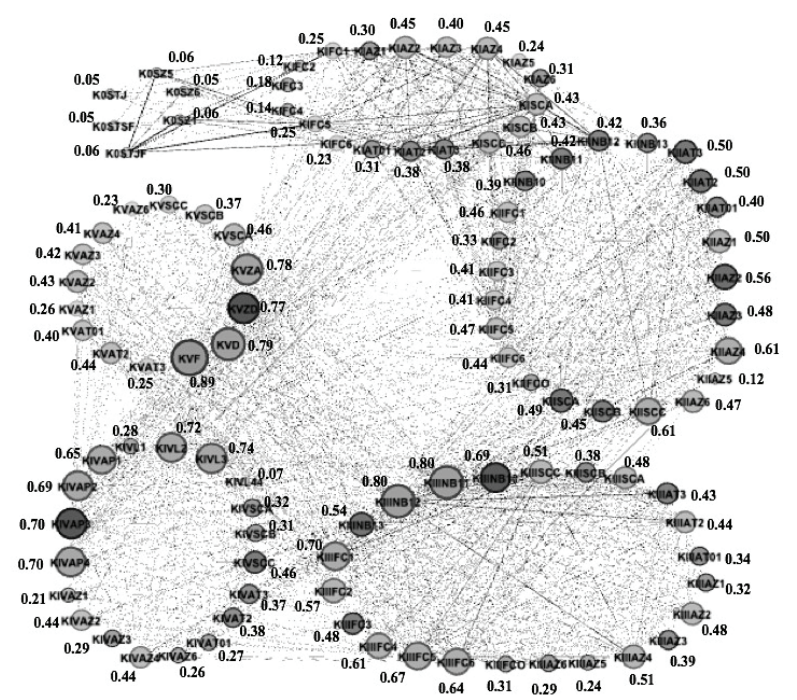

FIGURE 3. Network with Eigenvector Centrality for all variables related to the efficacy 2 in women's volleyball. Terminology: in each node, codes are represented by the name of complex (e.g., KII), followed by the variable and its category (e.g., KIIAZ6 indicates that the action occurred in complex II, the variable in question was Attack Zone, and the category is Zone 6). Codes for the different variables: IPS - Initial Position of the Serve; ST - Serve Type (Jump, Jump-Float and Standing-Float); FC - Zone of First Contact; SC Setting Condition; AZ -Attack Zone; AT - Attack Tempo; BO - Block Opposition; KIVB - Number of Available Player Before of Attack Coverage; KIVL - Number of Coverage Lines; KVD and KVF - Downball and Freeball; KVTZ -Target Zone in KV (Attack or Defence Zone).

Our results further highlighted, for Efficacy 2 (i.e., point): (i) Serve Type Jump Float (0.06) in K0. (ii) Setting Condition
C in KI (0.46), KII (0.61), KIII (0.51) and KIV (0.46); SCA in KV (0.48); (iii) Attack Zones 4 and 2 in KI (0.45 and 0.45 re- 
spectively), KII $(0.61,0.56)$, KIII $(0.51,0.48)$, KIV $(0.44,0.44)$; Attack Zone 2 in KV (0.43); (iv) Attack Tempo 3 in KI (0.38), KII (0.50), KIII (0.44), KIV (0.38), and KV (0.44).

\section{Discussion}

This study aimed to understand if game patterns impacted the efficacy of each play in high-level women's volleyball. While the mainstream view is that distinct game patterns affect the efficacy level (e.g., Marcelino et al. (2008)), a recent study by the authors of the present paper in high-level men's volleyball showed that game efficacy was independent of game patterns (Laporta et al., 2019). Here, we applied Social Network Analysis with a calculation of Eigenvector Centrality in women's volleyball, considering simultaneously direct and indirect gaming actions connections between the six functional game complexes (e.g., Laporta et al. (2018a, 2018b)) and analysing the three levels of efficacy.

Our results showed that game patterns were highly similar for all three levels of efficacy (i.e., the analysed variables and their relationships presented roughly the same behaviour regardless of efficacy level), as had happened with our study in men's volleyball (Laporta et al., 2019). First and foremost, playing under non-ideal conditions (i.e., Setting Condition C) was a core feature associated with all efficacy levels (E0, 1 and 2) in Complexes I to IV. These findings evidence the need for teams to be capable of playing a large portion of time under non-ideal or off-system conditions, and therefore reinforcing the conclusions of previous studies in women's volleyball (Hurst et al., 2016; Laporta et al., 2018a, 2018b). However, in $\mathrm{KV}$ (i.e., freeball, usually representing good conditions for the realization of the first contact) setting occurred most commonly under ideal conditions (i.e., Setting Condition A), but also regardless of efficacy level. These results concur to suggest that individual skill may overcome collective game patterns. Additionally, attacks on the extremities of the net (i.e., Zones 4 and 2) and using slower attack tempos (i.e., Tempos 2 and 3) were central across all efficacy levels, as had occurred in men's volleyball (Laporta et al., 2019).

Notwithstanding, our results differ from those found in men's volleyball in some respects, namely previous studies in men also applying SNA with Eigenvector Centrality (Laporta et al. 2019). In women's top-level, Jump-Float Serve had higher eigenvector values associated with increasing effectivity and also with continuity, which corroborates previous studies, also in women volleyball; however, this serve type is more frequently used and also more effective in women's volleyball than Jump Serve (Hurst et al., 2016; Palao, Manzanares, and Ortega, 2009). In addition, serving from the middle backcourt (i.e., Zone 6) caused lower continuity and scoring values in top-level women's volleyball, unlike what was observed in men's volleyball (Laporta et al., 2019). In men's volleyball, due to the greater use of Jump Serve (service with greater power), the serve performed in Zone 6 does not favour this execution, in which the athlete's trajectories are reduced by the centralized position in the backcourt. However, some authors argue that Serve Zones 1 and 5 are the most frequently used zones, as athletes tend to serve behind the zones that they will subsequently occupy for defence; specifically, there is a decrease in the athlete's displacement, making the arrival in the defence zone faster (Loureiro et al., 2017; Quiroga et al., 2010). In addition, these areas can increase the ball trajectories' distance (diagonal paths) decreasing the error probability and increas- ing the point probability, wherein the server can use a greater distance to increase the serve intensity, search for conflict zones between two receivers, as well as use vulnerable spaces to hinder the movement of some players.

Women's volleyball has a characteristic of playing with a certain degree of security, augmenting the values of continuity actions and thus increasing the number of actions in the transition phase (KII and KIII) compared to men's volleyball (Costa et al., 2012; Kountouris, Drikos, Aggelonidis, Laios, \& Kyprianou, 2015). In this study, the complexes that present less risk and greater security are Complexes I, II and III, and the safe attack zone in which the athletes appear to control the risk is in Attack Zone 4. While Complexes IV and V revealed a tendency to reverse this pattern, with the attack being performed mostly in Zone 2. We note that when this attempt to reverse this pattern occurred in these two rarely occurring complexes, the risk was increased and in less favourable situations (such as in KIV) thus increasing the values associated with continuity and error of the actions. This result may be associated with off-system play (extremities zones and Setting Conditions C) and the opposite player importance in men's volleyball (G. D. C. Costa et al., 2016), while facing easier conditions they attack by riskier zones (e.g., zone 2).

In addition, although men use more power in attack actions, they have tended to play a slower game, with Tempo 3 predominating (Laporta et al., 2018a; Loureiro et al., 2017), women presented a tendency of playing a safer game (Hurst et al., 2016), with more predictable attack zones but intending to increase the unpredictability through of game speed diversity (different Attack Tempos), for which the intermediate attack tempo (AT 2) presented high centrality values in the majority of the game complexes. The data also suggested that women's volleyball seems to present greater predictability with regard to the playing space (Attack Zones) while increasing the risk through the playing speed (Attack Tempo), in comparison with our previous study in men's volleyball (Laporta et al., 2019).

The results further reinforced the notion that, in high-level volleyball's attack, individuals' skills may play a more relevant role than game patterns, at least where play efficacy is considered. Since volleyball does not allow invasion of the opponent's court, the blocker cannot interfere directly with the attacker's action, which might explain this result. Therefore, our results suggest that perhaps the attacker's individual skill and privilege of contacting the ball first might surpass the importance of how the play unfolded up until that moment. If future studies confirm this, it might support the perceptions that high-level setters have concerning the momentum of each attacker during a set or match (Mesquita \& Graça, 2002; Queiroga et al., 2005).

Overall, our results support the utilization of SNA and Eigenvector Centrality to understand game patterns and also highlight the importance of individual skill in determining attack efficacy in high-level women's volleyball, since game patterns were extremely similar across all levels of play efficacy. It is further highlighted that women's volleyball is predictable in relation to the playing space, increasing the risk through game speed. Future studies should evaluate how situational constraints impact upon individual actions (e.g., match status, results or previous individual actions by the same player, type of set, home vs away match, among other possibilities). We further recommend that this research is replicated in different competitions and playing levels, to understand whether this 
represents a strong feature inherent to volleyball or an idiosyncrasy of a few selected samples.

\section{References}

Afonso, J., \& Mesquita, I. (2011). Determinants of block cohesiveness and attack efficacy in high-level women's volleyball. European Journal of Sport Science, 11(1), 69-75.

Bonacich, P., \& Lloyd, P. (2001). Eigenvector-like measures of centrality for asymmetric relations. Social Networks, 23(3), 191-201.

Costa, G. D. C., Ceccato, J. S., de Oliveira, A. S., de Britto Evangelista, B. F., de Oliveira Castro, H., \& Ugrinowitsch, H. (2016). Men's Volleyball Height Level: Association between Game Actions on the Side-Out |Voleibol Masculino de Alto Nível: associação entre as ações de jogo no side-out|. Journal of Physical Education, 27(1).

Costa, G., Afonso, J., Brant, E., \& Mesquita, I. (2012). Differences in game patterns between male and female youth volleyball. Kinesiology, 44(1), 60-66.

Cotta, C., Mora, A. M., Merelo, J. J., \& Merelo-Molina, C. (2013). A network analysis of the 2010 FIFA world cup champion team play. Journal of Systems Science and Complexity, 26(1), 21-42.

Duch, J., Waitzman, J. S., \& Amaral, L. A. N. (2010). Quantifying the Performance of Individual Players in a Team Activity. PLoS ONE, 5(6), e10937. doi:10.1371/ journal.pone.0010937

Fleiss, J. L., Levin, B., \& Paik, M. C. (2013). Statistical methods for rates and proportions: John Wiley \& Sons.

Freeman, L. C. (1979). Centrality in social networks conceptual clarification. Social Networks, 1(3), 215-239.

Hurst, M., Loureiro, M., Valongo, B., Laporta, L., Nikolaidis, P. T., \& Afonso, J. (2016). Systemic Mapping of High-Level Women's Volleyball using Social Network Analysis: The Case of Serve (K0), Side-out (KI), Side-out Transition (KII) and Transition (KIII). International Journal of Performance Analysis in Sport, 16(2).

Kountouris, P., Drikos, S., Aggelonidis, I., Laios, A., \& Kyprianou, M. (2015). Evidence for Differences in Men's and Women's Volleyball Games Based on Skills Effectiveness in Four Consecutive Olympic Tournaments. Comprehensive Psychology, 4, 30.50. CP. 34.39.

Laporta, L., Afonso, J., \& Mesquita, I. (2018a). Interaction network analysis of the six game complexes in high-level volleyball through the use of Eigenvector Centrality. PLoS ONE, 13(9), e0203348. doi: 10.1371/journal.pone.0203348

Laporta, L., Afonso, J., \& Mesquita, I. (2018b). The need for weighting indirect connections between game variables: Social Network Analysis and eigenvector centrality applied to high-level men's volleyball. International Journal of Performance Analysis in Sport, 18(6), 1067-1077. doi: 10.1080/24748668.2018.1553094

Laporta, L., Afonso, J., Valongo, B., \& Mesquita, I. (2019) Using social network analysis to assess play efficacy according to game patterns: a game-centred approach in high-level men's volleyball. International Journal of Performance Analysis in Sport, 19(5), 866-877. doi:

\section{$10.1080 / 24748668.2019 .1669007$}

Laporta, L., Nikolaidis, P., Thomas, L., \& Afonso, J. (2015). The Importance of Loosely Systematized Game Phases in Sports: The Case of Attack Coverage Systems in HighLevel Women's Volleyball. Montenegrin Journal of Sports Science and Medicine, 4(1), 19-24.

Loureiro, M., Hurst, M., Valongo, B., Nikolaidis, P., Laporta, L., \& Afonso, J. (2017). A Comprehensive Mapping of HighLevel Men's Volleyball Gameplay through Social Network Analysis: Analysing Serve, Side-Out, Side-Out Transition and Transition. Montenegrin Journal of Sports Science and Medicine, 6(2), 35-41.

Marcelino, R., Mesquita, I., \& Afonso, J. (2008). The weight of terminal actions in volleyball. Contributions of the spike, serve and block for the teams' rankings in the World League 2005. International Journal of Performance Analysis in Sport, 8(2), 1-7.

Marcelino, R., Sampaio, J., \& Mesquita, I. (2011). Investigação centrada na análise do jogo: da modelação estática à modelação dinâmica.[Research on the game analysis: from static to dynamic modeling]. Revista Portuguesa de Ciências do Desporto, 11(1), 481-499.

Mesquita, I., \& Graça, A. (2002). Probing the strategic knowledge of an elite volleyball setter: a case study. International Journal of Volleyball Research, 5(1), 13-17.

Mesquita, I., Palao, J. M., Marcelino, J., \& Afonso, J. (2013). Performance Analysis in indoor volleyball and beach volleyball (T. McGarry, P. O’Donoghue, \& J. Sampaio Eds.). Oxon: Routledge.

O'Donoghue, P. (2009). Research methods for sports performance analysis. New York: Routledge.

Palao, J. M., Manzanares, P., \& Ortega, E. (2009). Techniques used and efficacy of volleyball skills in relation to gender. International Journal of Performance Analysis in Sport, 9(2), 281-293.

Queiroga, M., Matias, C., Greco, P., Graça, A., \& Mesquita, I. (2005). The dimension of the high-level setter's tactical strategic knowledge: Study with setters of Brazilian national teams. Brazilian Journal of Physical Education, Special Edition, 111-119.

Quiroga, M. E., García-Manso, J. M., Rodríguez-Ruiz, D., Sarmiento, S., De Saa, Y., \& Moreno, M. P. (2010). Relation between in-game role and service characteristics in elite women's volleyball. The Journal of Strength \& Conditioning Research, 24(9), 2316-2321.

Silva, M., Marcelino, R., Lacerda, D., \& João, P. V. (2016). Match Analysis in Volleyball: a systematic review. Montenegrin Journal of Sports Science and Medicine, 5(1), 35-46.

Wäsche, H., Dickson, G., Woll, A., \& Brandes, U. (2017). Social network analysis in sport research: an emerging paradigm. European Journal for Sport and Society, 14(2), 138-165.

Wasserman, S., \& Faust, K. (1994). Social network analysis: Methods and applications (Vol. 8). Cambridge University Press.

Yamamoto, Y., \& Yokoyama, K. (2011). Common and unique network dynamics in football games. PLoS ONE, 6(12), e29638. 